\title{
Fluorescent ZnS Quantum Dots-Phosphoethanolamine Nanoconjugates for Bioimaging Live Cells in Cancer Research
}

\author{
Alexandra A. P. Mansur, ${ }^{\dagger}$ Herman S. Mansur, ${ }^{*}{ }^{\dagger}$ (๑) Sandhra M. Carvalho, ${ }^{\dagger,}{ }^{\ddagger}$ Zélia I. P. Lobato, $^{\dagger}$ \\ Maria de Fátima Leite, ${ }^{\S}$ and Lorena L. Mansur ${ }^{\dagger, \ddagger}$
}

${ }^{\dagger}$ Center of Nanoscience, Nanotechnology and Innovation-CeNano ${ }^{2}$ I, ${ }^{\ddagger}$ Department of Preventive Veterinary Medicine, Veterinary School, and ${ }^{\S}$ Department of Physiology and Biophysics, ICB, Federal University of Minas Gerais-UFMG, Av. Antônio Carlos, 6627 Belo Horizonte/MG, Brazil

\section{Supporting Information}

\begin{abstract}
Many human diseases, including metabolic, immune, and central nervous system disorders, as well as several types of cancers, are the consequence of an important alteration in lipid-related metabolic biomolecules. Although recognized that one of the most important metabolic hallmarks of cancer cells is deregulation of lipid metabolism, the multiple complex signaling pathways are poorly understood yet. Thus, in this research, novel nanoconjugates made of $\mathrm{ZnS}$ quantum dots (QDs) were directly synthesized in aqueous media using phosphoethanolamine (PEA) as the capping ligand, which is an important biomolecule naturally present in cells for de novo biosynthesis of fatty acids and phospholipids involved in the cell structure (e.g., membrane), differentiation, and cancer growth. These QDPEA bio-nanoconjugates were characterized by spectroscopical and morphological techniques. The results demonstrated that fluorescent $\mathrm{ZnS}$ nanocrystalline QDs were produced with uniform spherical morphology and estimated sizes of $3.3 \pm 0.6 \mathrm{~nm}$. These nanoconjugates indicated core-shell colloidal nanostructures (ZnS QD-PEA) with the hydrodynamic diameter $\left(H_{\mathrm{D}}\right)$ of $26.0 \pm 3.5 \mathrm{~nm}$ and $\zeta$-potential centered at $-30.0 \pm 4.5 \mathrm{mV}$. The cell viability response using mitochondrial activity assay in vitroconfirmed no cytotoxicity at several concentrations of PEA (biomolecule) and the $\mathrm{ZnS}-\mathrm{PEA}$ nanoconjugates. Moreover, these nanoconjugates effectively behaved as fluorescent nanomarkers for tracking the endocytic pathways of cancer cells using confocal laser scanning microscopy bioimaging. Hence, these results proved that biofunctionalized ZnS-PEA nanoprobes offer prospective tools for cellular bioimaging with encouraging forecast for future applications as active fluorescent biomarker conjugates in metabolic-related cancer research.
\end{abstract}

\section{INTRODUCTION}

From the 20th century and ahead, cancer research has experienced remarkable advances in the areas of diagnosis and treatment, which were made possible by the combination of distinct domains of knowledge. New understandings of life sciences, including cellular and molecular biology, were associated with engineering, materials science, chemistry, informatics, and physics, leading to innovative technologies for imaging and diagnostic tools. ${ }^{1-4}$ However, cancer remains as one of the most devastating diseases of the current century posing great challenges to scientists and health professionals. ${ }^{1-3}$ Consequently, new strategies for fighting cancer have emerged, such as alterations in cell metabolism (e.g., lipids and sugars), which are increasingly acknowledged as important aspects of malignant tumors and may serve for the identification of new therapeutic targets. ${ }^{5}$ Moreover, there is growing evidence that cancer cells demonstrate specific variations in distinct parts of lipid metabolism where elevated levels of the phospholipid precursors phosphocholine and phosphoethanolamine (PEA) were detected. To strengthen these features, recent studies have identified that deregulation of lipid metabolism is one of the most important metabolic hallmarks of cancer cells. ${ }^{6-9}$ In addition, modifications in the metabolism of lipids can cause disruption of several cellular processes, including cell growth, proliferation, differentiation, and motility. Moreover, enhancing de novofatty acid (FA) synthesis, increasing lipid uptake, and lipolysis have also been considered as means of FA acquisition in cancer cells. In contrast to most untransformed healthy tissues, which naturally satisfy their demand from dietary lipids, cancer cells frequently re-activate de novo lipogenesis. ${ }^{6-16}$ Liu et al. ${ }^{10}$ published an interesting review highlighting that targeting lipid metabolism is a promising strategy for the development of novel diagnostic and therapeutic options against human cancer. ${ }^{5-10}$

In this scenario, nanotheranostics combining diagnosis and therapy of cancer by using nanoscience and nanotechnology

Received: August 19, 2018

Accepted: November 5, 2018

Published: November 16, 2018 


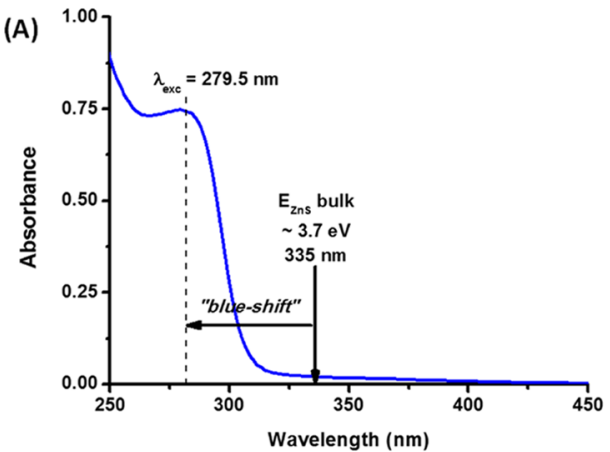

(B)

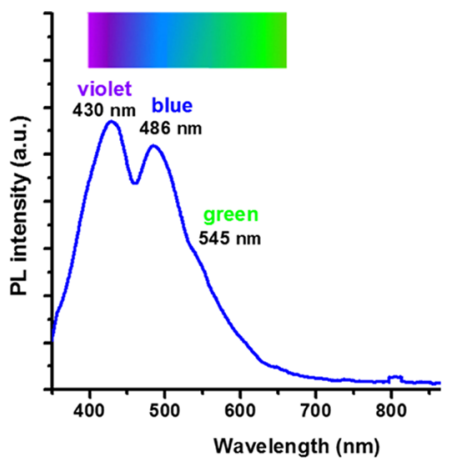

(C)

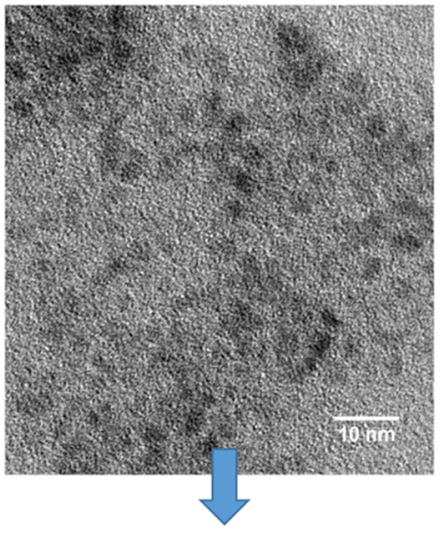

(D)

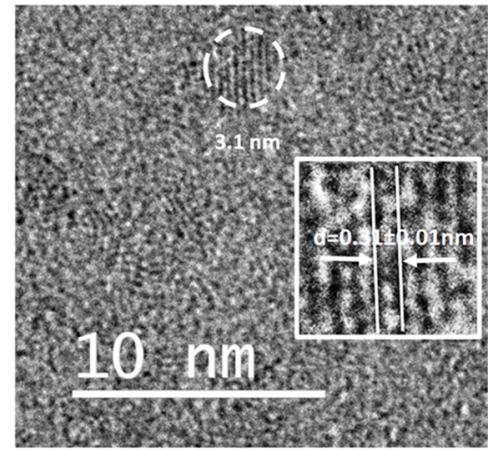

(E)

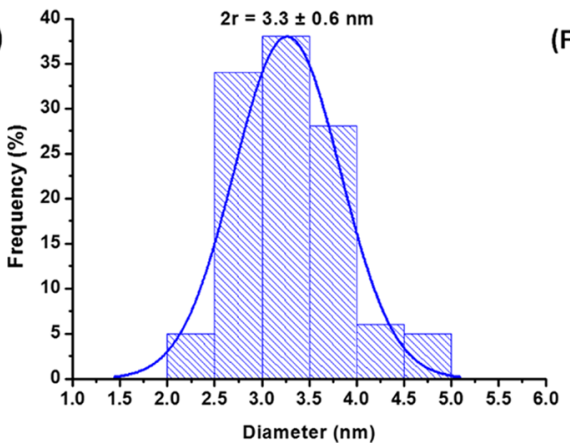

(F)

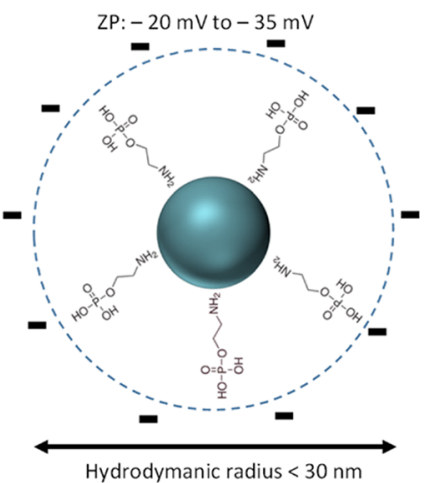

Figure 1. ZnS-PEA QDs characterization: (A) UV-vis spectroscopy; (B) PL spectroscopy; (C) TEM image; (D) HRTEM image with the typical QD size (diameter) and nanocrystal lattice fringes (ED pattern); (E) histogram of nanoparticle size distribution; and (F) schematic representation of QDs with indication of ZP and hydrodynamic radius.

approaches offers the ability to engineer nanomaterials to interact with cancer cells at the molecular level, which can significantly improve the current knowledge about cellular metabolism and more effectiveness and specificity on detection and therapy of cancers. ${ }^{15-20}$ Therefore, the development of novel nanomaterials for live cell bioimaging assays has gained crescent interest to assessing the intricate cellular pathways and complex metabolic mechanisms of cancer cells and tumor behavior. ${ }^{17-20}$ Among several alternatives of low dimension materials (i.e., $0 \mathrm{D}, 1 \mathrm{D}$, and $2 \mathrm{D}$ or nanomaterials), colloidal semiconductor nanocrystals (referred to as quantum dots, QDs) have been intensively investigated for a broad range of biomedical and pharmaceutical applications. Essentially, QDs are extremely small semiconductor nanocrystals that possess a unique set of optical, electronic, and physicochemical properties. $^{21-23}$ Thus, QD conjugates (i.e., inorganic core and biomolecule shell) are widely used as nanoprobes for cell imaging and sensing as they present strong fluorescent behavior combined with very narrow emission band, high chemical stability, and biochemical specificity. Yet, despite almost 3 decades since the first report of QDs synthesis, they are predominantly produced based on cadmium-containing (e.g., CdS, CdS, and CdTe) nanocrystals using hazardous organometallic routes at high temperatures, which has increased the biological and environmental concerns regarding their toxicity. To overcome these major drawbacks, the development of "Cd-free" QDs such as zinc chalcogenides (i.e., $\mathrm{ZnS}$ and $\mathrm{ZnSe}$ ) using the aqueous colloidal process has gained increasing attention mostly because of their intrinsic biological and environmental compatibilities. ${ }^{21-23}$ Another key aspect to be considered is associated with the chemical stability of these ultrasmall nanoparticles because of their high tendency to grow for minimizing their free energy, which would cease their optical properties related to the quantum-size confinement (i.e., bigger than Bohr radius). This characteristic can be achieved by the rational selection of ligands acting simultaneously as capping agents for limiting the nanocrystal growth and agglomeration combined with biological functions. ${ }^{21-25}$ 
The presence of chemical functional groups and the length of these molecules play pivotal roles in the overall nucleation and stabilization process of nanoconjugates. Therefore, the functionalization of the surfaces of "heavy metal-free" QDs is of crucial importance not only to increase their water-solubility and chemical stability but also to assure nontoxicity and allowing further conjugation with biochemical entities such as biomarkers (e.g., nucleic acids, sugars, small metabolites, proteins, enzymes, antibodies, etc.) for specific tracking and targeting of cancer cells. ${ }^{15,18-20,23,26,27}$ To this end, QD-based nanotheranostic strategy is an exceptional platform for the development of multifunctional nanomaterials that may potentially be used to target cancer cells for the early diagnosis, tracking, and treatment of specific malignant tumors. Nonetheless, only few studies have been published in the literature using QD-conjugates based on lipids, phospholipids, and derivatives for sensing, monitoring, and tracking biological processes of cancer cells, possibly due to the insolubility of these molecules in water. ${ }^{28,29}$ For that reason, most commonly, colloidal QDs prepared in aqueous media are stabilized by water-soluble molecules such as amino acids, peptides, polymers, and amphiphilic moieties, where the length and functional chemical groups of the (macro)molecules play a pivotal role in the overall stability of the nanocolloids.

Thus, in this study, we endeavor to design and synthesize for the first time, novel ZnS QD nanoconjugates directly produced using PEA as the capping ligand and the functional biomolecule in a one-pot aqueous colloidal process. Additionally, the PEA molecule has suitable water solubility to be used for colloidal synthesis of nanoconjugates, which is dissimilar from most FAs and lipid-related biomolecules. The results demonstrated that fluorescent ZnS QDs were produced with monodisperse spherical morphology rendering water-soluble inorganic-organic core-shell colloidal nanostructures ( $\mathrm{ZnS}-$ PEA). Moreover, the in vitro cell viability assays based on mitochondrial activity evidenced that they were nontoxic to five cancer cell lines. As a proof-of-concept, these bioconjugates behaved as optically active fluorescent nanoprobes for monitoring and tracking cancer cell uptake using confocal laser microscopy bioimaging. Therefore, this study evidenced that the biofunctionalized $\mathrm{ZnS}-\mathrm{PEA}$ nanoconjugates presented promising perspectives "shining light" for cellular bioimaging in metabolic-related cancer research.

\section{RESULTS AND DISCUSSION}

2.1. Characterization of ZnS-PEA Nanoconjugates. It is widely known that the toxicity of materials at the nanoscale dimension (i.e., nanomaterials) is very complex and not completely understood, because it is affected by numerous reasons, including chemical composition, shape, dimension, surface features, and charge..$^{30,31}$ Therefore, it is of paramount importance to comprehensively characterize the morphological features and physicochemical properties of the nanoconjugates made of $\mathrm{ZnS}$ QDs with the surface capped by PEA ligands. The $\mathrm{ZnS}$ QDs biofunctionalized with PEA were characterized by UV-visible spectroscopy (UV-vis), photoluminescence (PL) spectroscopy, high-resolution transmission electron microscopy (HRTEM) with selected area electron diffraction (SAED), zeta potential (ZP), and dynamic light scattering (DLS), and the results are summarized in Figure 1. Primarily, UV-visible spectroscopy was used for performing in situ characterization of the formation of QDs as colloidal conjugates and their stabilization in the aqueous medium
(Figure 1A). The results evidenced the production of $\mathrm{ZnS}$ nanocrystals with an average diameter of $2 r=3.2 \mathrm{~nm}$ considering the empirical model, ${ }^{32,33}$ which correlates the nanoparticle size $(r)$ to the optical band gap $\left(E_{\mathrm{QD}}\right)$ from a UV-vis spectrum (Equation 1). Importantly, these UV-vis results proved that $\mathrm{ZnS}$ QDs were effectively produced in this process using PEA as ligand based on the blue shift of band gap energy (i.e., higher energy, $E_{\mathrm{QD}}=4.1 \mathrm{eV}$ ) compared to the bulk value of $\mathrm{ZnS}$ semiconductor $\left(E_{\mathrm{ZnS}} \approx 3.7 \mathrm{eV}\right)$.

$$
\begin{aligned}
r\left(E_{\mathrm{QD}}\right)= & {\left[0.32-2.9 \times\left(E_{\mathrm{QD}}-3.49\right)^{1 / 2}\right] / 2 } \\
& \times\left(3.50-E_{\mathrm{QD}}\right)
\end{aligned}
$$

The PL spectroscopy evidenced the production of $\mathrm{ZnS}-$ PEA conjugates with strong emission in the visible range of spectrum, predominantly related to violet-green colors (Figure 1B), which are commonly associated with the nonradiative recombination of charges. ${ }^{21}$ These findings are very important considering the original design of these $\mathrm{ZnS}-\mathrm{PEA}$ nanoconjugates aiming at applications as fluorescent bioprobes for tracking cell metabolic pathways and signaling events. They were produced using a green one-pot aqueous synthesis, offering the advantages of improved simplicity/reproducibility and no detectable toxicity [i.e., 3-[4,5-dimethylthiazol-2-yl]2,5-diphenyl tetrazolium bromide (MTT) assays in following sections], compared to the traditional organometallic process at harsh and highly toxic conditions. Additionally, these nanoconjugates behaved as "heavy-metal-free" fluorophores based on ZnS QDs, which are usually considered benign (i.e., cyto-friendly and eco-friendly) for multifunctional bioapplications. The quantum yield (QY) of the $\mathrm{ZnS}-\mathrm{PEA}$ nanoconjugates was estimated to be typically $\sim 1.0 \%$, in good agreement with the reported literature of "Cd-free" QDs synthesized at low temperatures and aqueous colloidal process. Different from processes using high temperatures and organometallic media, the aqueous colloidal synthesis of QDs frequently leads to higher density of surface defects that act as "trap states" in the recombination process of charges. Nevertheless, it widely known that the QY can be significantly improved by postsynthesis thermal annealing at a higher temperature and by growing a semiconductor shell for passivating the surface defects. ${ }^{26,34}$

Typical TEM image (Figure 1C) indicated the formation of uniformly dispersed spherical nanoparticles with estimated sizes of $d=3.3 \pm 0.6 \mathrm{~nm}$ (Figure $1 \mathrm{E}$ ), very coherent with the dimensions of ZnS QDs estimated by UV-vis measurements (i.e., $2 r=3.2 \mathrm{~nm}$ ). Additionally, HRTEM images associated with SAED diffraction patterns (Figure 1D) confirmed the formation of crystalline semiconductor nanoparticles wellmatched with $\mathrm{ZnS}$ cubic structure (i.e., lattice (111), $d=0.31$ $\pm 0.01 \mathrm{~nm}$ ).

In order to further clarify these findings related to the formation nanocolloids in water media, it is crucial to examine the physicochemical properties evaluated through the DLS method and $\zeta$-potential analysis (Figure 1F). Thus, the hydrodynamic diameter $\left(H_{\mathrm{D}}\right)$ of the $\mathrm{ZnS}$ QD-PEA nanoconjugates was $26.0 \pm 3.5 \mathrm{~nm}$ and $\zeta$-potential values ranged from $-20.0 \mathrm{mV}(\mathrm{pH}=7.4)$ to $-35.0 \mathrm{mV}$ (at $\mathrm{pH}=8.5)$. These values were attributed to the formation of conjugated nanostructures made of inorganic semiconductor $\mathrm{ZnS}$ QD (core) surrounded by the organic PEA capping ligand (shell). The overall dimension estimated by DLS is ascribed to contribution of the inorganic inner core of $\mathrm{ZnS}$ QD $(\sim 3.3 \mathrm{~nm})$ 
added to the organic outer layer of PEA and solvated in water medium, considering the effects of the electrostatic charges and chemical interactions of functional groups of the biomolecule. These results are interpreted bearing in mind the potential applications of these $\mathrm{ZnS}-\mathrm{PEA}$ conjugates in nanotheranostics, simultaneously as fluorescent nanoprobes for cell bioimaging and functional nanocarriers for therapy of cancer cells. Considering that the toxicity of nanomaterials (or nanotoxicity) is very complex and known to be affected by their dimension and shape (i.e., sizes $<100 \mathrm{~nm}$ ), where the smaller the nanoparticulate system, the higher is the cellular uptake and, therefore, the possibility of cell endocytosis mechanisms. $^{30,31}$ Thus, the spherical morphology of ZnS QDPEA combined with the very small $H_{\mathrm{D}}$ dimension assessed by DLS $(<30 \mathrm{~nm})$ favored the cancer cell uptake and, if harmful, would have caused higher cell death detectable via cell viability assays (i.e., reduction of mitochondrial activity). In addition, using the same rational approach, the cell internalization analysis of the nanoconjugates needs to take into account the electrostatic charges of the system, where PEA is the outer layer. Essentially, PEA is a small biomolecule and $\mathrm{pH}$ dependent because of the presence of ionizable phosphates and amine groups $\left(\mathrm{NH}_{2}+\mathrm{H}^{+} \rightarrow \mathrm{NH}_{3}^{+}\right)$, which can be protonated and deprotonated by the acidic or alkaline conditions of the medium and also by the cell microenvironment. ${ }^{35}$ Thus, based on the $\zeta$-potential measurements $(>-20$ $\mathrm{mV}$, at physiological $\mathrm{pH})$, the results demonstrated the formation of net negatively charged colloidal nanostructures, which are expected to reduce their interactions with the negative potential of cell plasma membranes. ${ }^{36-38}$ However, besides the nature of the charge, charge density and hydrophobicity are similarly important, where phagocytic cells favorably take up anionic nanoparticles. Moreover, it has been reported that cells do not use different uptake routes for cationic and anionic nanoparticles. Although positive charges on the nanomaterials seem to enhance the efficacy of cell imaging, drug delivery, and gene transfer, it has been reported that cationic nanoparticles can cause a more pronounced disruption of plasma-membrane integrity, bigger mitochondrial, and lysosomal damages than anionic nanoparticles. ${ }^{36-39}$ Therefore, the common theory that the preferential cellular uptake of positively charged nanoparticles compared to neutral or negatively charged nanoparticles is due to favorable electrostatic interactions with cell membrane appears over simplistic and reductive. ${ }^{38}$ Unquestionably, despite the intensive research efforts, the published reports on the cellular responses to nanomaterials are frequently controversial due to the fact that relationships between the cell type and the broad set of nanomaterial properties are very complex and not completely understood. ${ }^{39}$ To this end, as far as the physicochemical properties and morphological aspects are concerned, these new $\mathrm{ZnS}$ QD-PEA nanoconjugates fulfilled most of key requirements for biomedical applications as fluorescent nanoprobes and nanosensors associated with biofunctionalized surfaces for bioimaging and tracking cancer cells.

2.2. Nanoconjugates for Cell Bioimaging and Tracking. 2.2.1. In Vitro Cell Viability Assays Using Cancer Cell Lines. Along with the most complete meta-analysis research recently reported, ${ }^{20}$ MTT cell viability test has been considered the major assay for in vitro assessment of cytotoxicity of QD-based nanomaterials for biomedical applications. Consequently, MTT bioassay was performed to evaluate the potential in vitro cell viability responses of PEA (biomolecule without conjugation) and $\mathrm{ZnS}-\mathrm{PEA}$ nanoconjugates toward normal and human cancer cell lines.

The results (Figure 2) evidenced no cytotoxicity at all concentrations of PEA (i.e., at $0.1,1.0,10$, and $100 \mu \mathrm{M}$ ) for
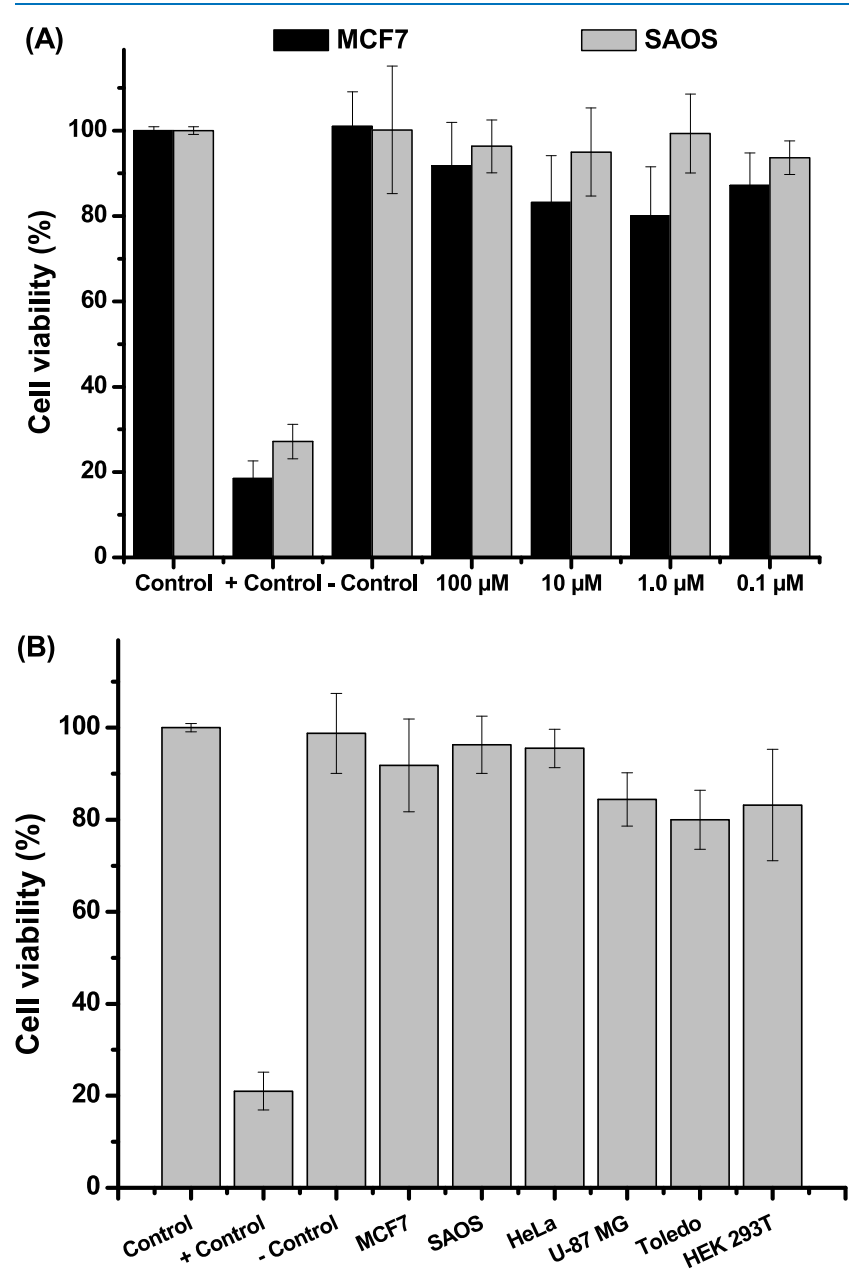

Figure 2. Cell viability responses by MTT assay after $48 \mathrm{~h}$ of incubation of (A) SAOS and MCF7 cell lines with PEA at different concentrations and (B) at concentration of $100 \mu \mathrm{M}$ with different cell types.

the normal (HEK 293T) and the five cancer cell types. In addition, there was no statistical difference of cell viability results between the concentrations for each cell type, where the average cell viability response was typically over $80 \%$ for all cancer cell types. Thus, considering the international standard (ISO 10933-5-Biological evaluation of medical devices-part 5: tests for in vitro cytotoxicity) and the literature, (nano)materials with cell viability results superior to $70 \%$ are considered noncytotoxic (in vitro) and preliminarily suitable for biomedical applications. Additionally, as a supporting evidence, doxorubicin (DOX), the gold standard as the chemotherapeutic drug for treating cancer tumors, ${ }^{4}$ was used as the reference of cytotoxic material for performing MTT assays at the same concentrations of PEA for the incubation period of $48 \mathrm{~h}$. The results are presented in Supporting Information (Figures $\mathrm{S} 1-\mathrm{S} 4$ ) and validated the expected high lethality of DOX anticancer agent in comparison to PEA, as reported by the literature. ${ }^{4}$ Toxicity was observed (i.e., cell 
viability $<70 \%$ ) for some of the cell lines even at the lowest concentration of drug tested $([\mathrm{DOX}]<0.1 \mu \mathrm{M})$.

Therefore, these results proved the absence of detectable in vitrocytotoxicity for PEA at the concentrations investigated, which can be attributed to the fact that it is a biological molecule commonly present in the lipid metabolism of mammals. Naturally, the conceivable toxicity of PEA at very high concentrations as an active biomolecule cannot be discarded, which can lead to some cell metabolism disorder or biochemical unbalance. In a similar way, in vitro MTT bioassays were performed using the $\mathrm{ZnS}-\mathrm{PEA}$ nanoconjugates incubated with the six cell lines (at $350 \mu \mathrm{M}$ equivalent of PEA biomolecule; $10 \mathrm{nM}$ of $\mathrm{ZnS}-\mathrm{PEA}$ colloidal nanoconjugates), and the results of cell viability are presented in Figure 3. It was
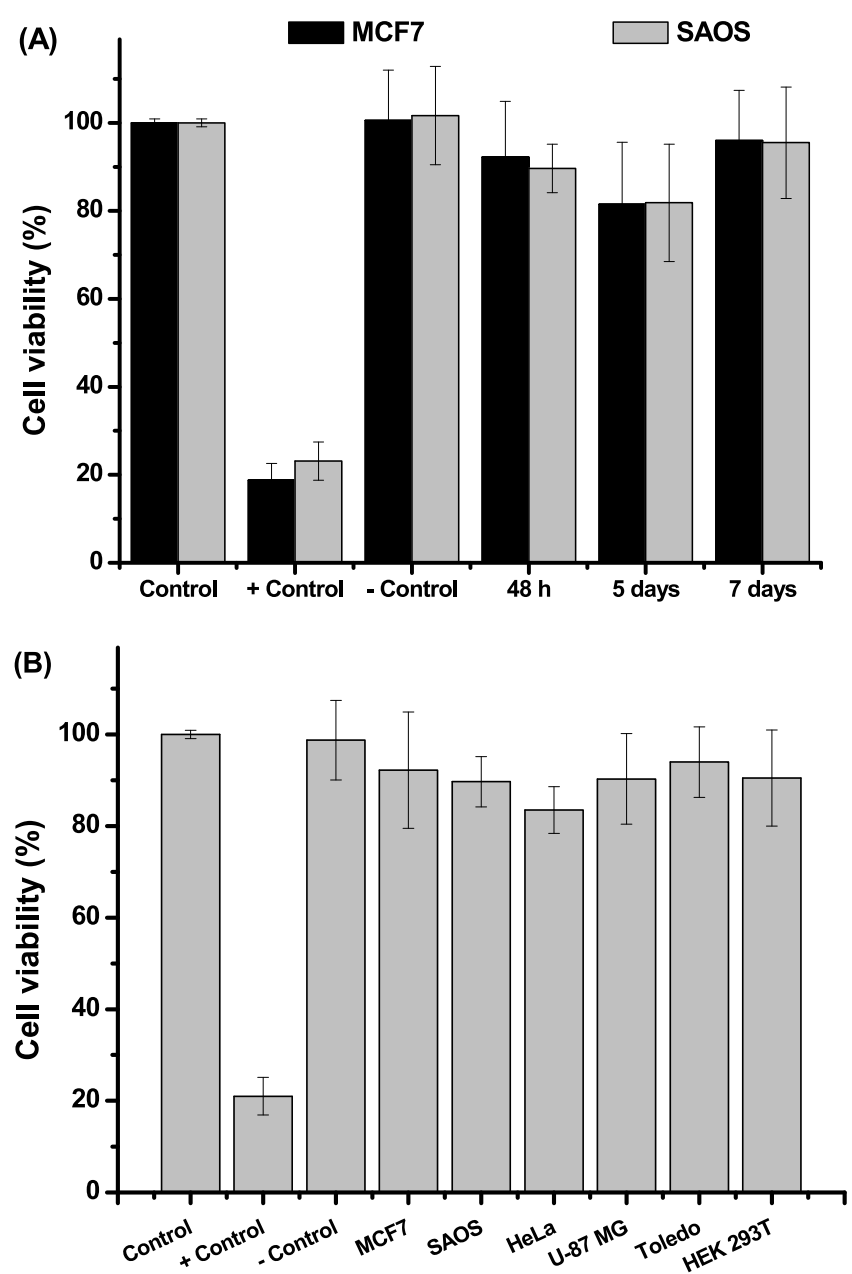

Figure 3. Cell viability responses by MTT assay of incubation of ZnS-PEA with SAOS and MCF7 cell lines for (A) $48 \mathrm{~h}, 5$ days, and 7 days and (B) after incubation with different cell lines for $48 \mathrm{~h}$ (at 350 $\mu \mathrm{M}$ equivalent of PEA biomolecule; $10 \mathrm{nM}$ of $\mathrm{ZnS}-\mathrm{PEA}$ colloidal nanoconjugates).

verified that no cytotoxic effect was detected for all 6 cell lines incubated for $48 \mathrm{~h}$ (Figure 3B), and even for 7 days of incubation no significant reduction of the cell viability responses (MCF7 and SAOS, Figure 3A) was detected. It is important to highlight that these findings validated the choice of using ZnS QDs based on their optical properties associated with the well-known nontoxicity compared to highly toxic conventional "Cd-containing" QDs (e.g., CdS and CdSe). In fact, zinc divalent cations $\left(\mathrm{Zn}^{2+}\right)$ are broadly found in nature in several forms, varying from mineral inorganic sources to living organisms as crucial metabolic species. Moreover, $\mathrm{Zn}^{2+}$ is one of the most present metallic ions in mammals second only to iron $\left.\left(\mathrm{Fe}^{3+}\right)\right)^{21,23}$ Therefore, these results confirmed the nontoxicity of $\mathrm{ZnS}$ QDs core ${ }^{23,40}$ as "Cd-free" nanomaterial, associated with the organic shell made of PEA producing cytocompatible fluorescent nanoprobes and/or nanosensors appropriate for prospective "safe" biomedical applications.

2.2.2. Fluorescent ZnS-PEA Nanoprobes for Bioimaging and Tracking of Cancer Cells. Nanomaterials have been the subject of intensive studies because of the growing interest for their wide range of potential applications in cancer research. Unfortunately, despite remarkable progress in the diagnosis and therapy of cancer in recent years, it remains one of the global leading causes of deaths, where the accurate early detection is considered of utmost importance for altering this scenario. To this end, nanotechnology based on fluorescent QDs offers a very promising platform for the progress of fighting cancer using molecular imaging systems for the earliest and most reliable diagnosis, tracking metabolism and functions of cancer cells, and improving the current imaging methods. Different techniques have been used for bioimaging and investigating cellular pathways in nanoparticle uptake research, including confocal laser scanning microscopy (CLSM), fluorescence microscopy, and conventional flow cytometry (FC). Generally, FC has been reported as one of the most accurate and reliable techniques for quantitative analyses of cellular processes and signaling mechanisms. ${ }^{23,24,27,40}$ Hence, considering the nanomaterial-based diagnosis strategy adopted in this work, non-cytotoxic $\mathrm{ZnS}-\mathrm{PEA}$ fluorescent bioconjugates were used for bioimaging and tracking the endocytosis pathway of cancer cells, where CLSM was used as characterization technique for bioimaging to be prospectively applied in future oncology research. Furthermore, these assays were designed focusing on capturing images at crescent time intervals for assessing the endocytic pathways as it is broadly known that endocytosis is the most common mechanism for internalizing nanosized particles and macromolecules by cells.

CLSM images were obtained after $0 \mathrm{~min}$ (control), 15, 30, and $60 \mathrm{~min}$ of incubation of SAOS (Figure 4) and MCF7 (Figure 5) cancer cell lines and HEK 293T (Figure 6) cells with $\mathrm{ZnS}-\mathrm{PEA}$ nanoconjugate. The internalization of $\mathrm{ZnS}-$ PEA nanoconjugates by SAOS, MCF7, and HEK 293T cells can be clearly observed, where green fluorescent emission was verified scattered within the cellular cytosol with a significant growth of the fluorescence intensities associated with the increase of incubation time which demonstrated that the nanoconjugates penetrated through cancer cell membranes allowing biolabeling. These effects can qualitatively be referred to as system "OFF", when no fluorescent emission was observed, and "ON", when fluorescent signals were detected, which resembles the typical behavior of a biosensor (nanobiosensor) based on the fluorescent output signal of the nanomaterial. Moreover, regarding to spatial distribution of $\mathrm{ZnS}-\mathrm{PEA}$ conjugates within the cells, Figure 7 presented that after $60 \mathrm{~min}$ of incubation, fluorescent signal was fairly uniformly scattered in the cellular cytosol and the cells demonstrated normal and clear morphology. No spatial gradients and vanishing of the fluorescence signals were detected for $\mathrm{ZnS}$ QD-PEA conjugates transported from plasma membrane to the nucleus. In addition, there was no evidence of fluorescence emission localized in the region of the cell nucleus. This is expected because QDs must be released 


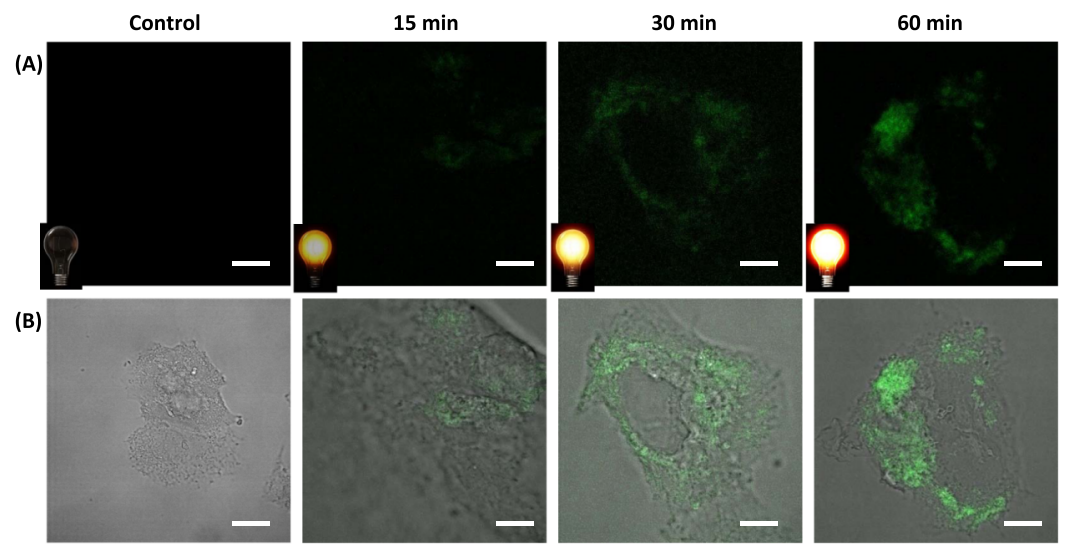

Figure 4. Confocal microscopy imaging of the cellular uptake of the ZnS-PEA nanoconjugates by MCF7 cells vs incubation time (15, 30 , and 60 min): (A) PL image and (B) PL + bright field image (scale bar $=10 \mu \mathrm{m}$ ).

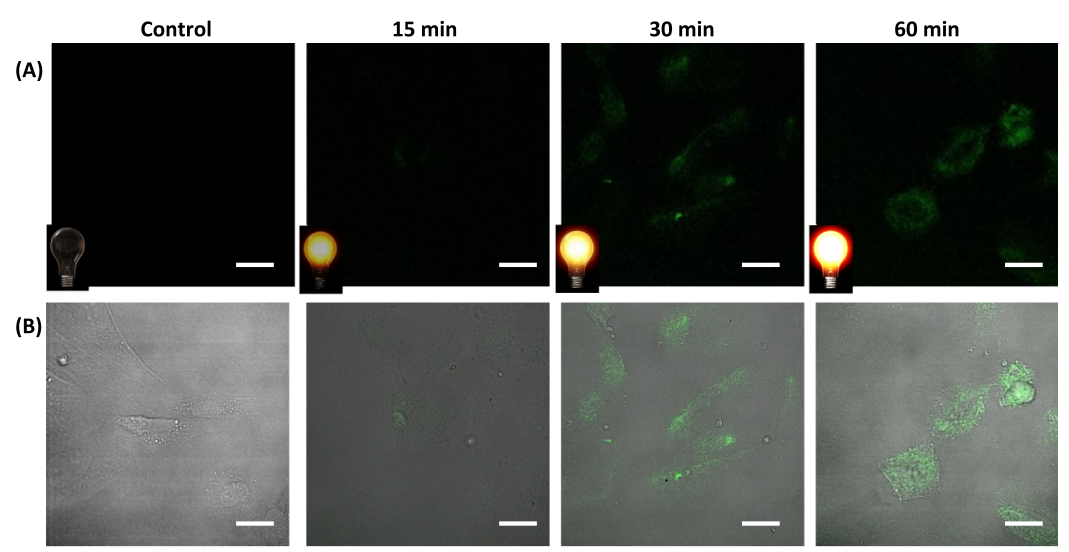

Figure 5. Confocal microscopy imaging of the cellular uptake of the $\mathrm{ZnS}-\mathrm{PEA}$ nanoconjugates by SAOS cells vs incubation time (15, 30 , and 60 min): (A) PL image and (B) PL + bright field image (scale bar $=10 \mu \mathrm{m}$ ).

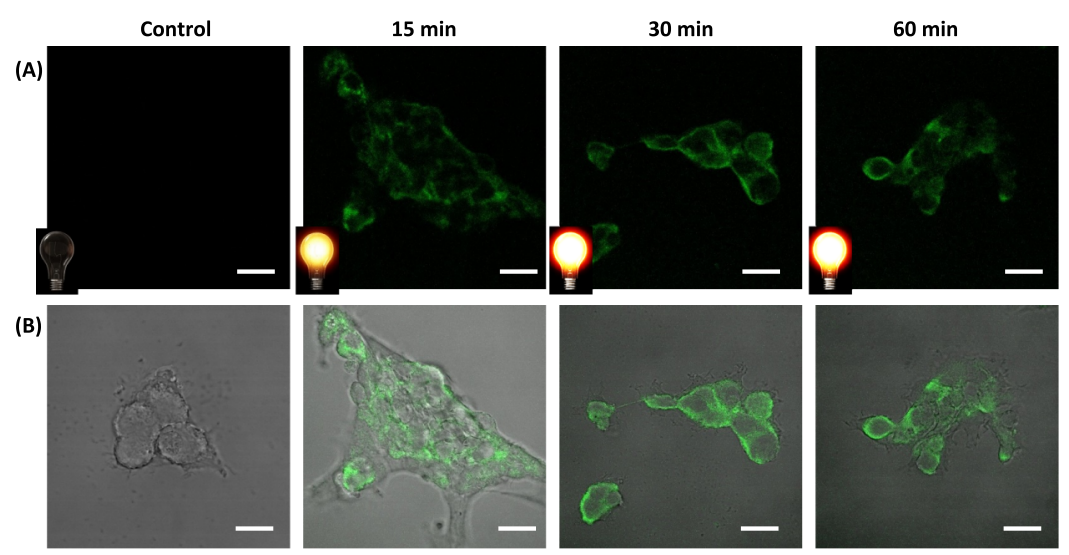

Figure 6. Confocal microscopy imaging of the cellular uptake of the ZnS-PEA nanoconjugates by HEK 293T cells vs incubation time (15, 30, and $60 \mathrm{~min}$ ): (A) PL image and (B) PL + bright field image (scale bar $=10 \mu \mathrm{m})$.

inside the cell cytosol to reach the nucleus and the escape of QDs from cytoplasmic vesicles into cytosol must be stimulated by irradiation with UV or blue light or by modifying QD surfaces with some moieties that induce vesicle rupture such as dipeptides, like ala-ala, ser-tyr, or tyr-ala. ${ }^{41}$

An additional complementary evidence of the presence of $\mathrm{ZnS}-\mathrm{PEA}$ nanoconjugates mostly distributed at the cytosol was based on the TO-PRO-3 staining procedure, which has a very strong binding affinity for double-stranded DNA at cell nuclei. ${ }^{4}$ The results of the DNA-staining based on typical fluorescence microscopy images for SAOS (A) and HEK 293T (B) cells after $60 \mathrm{~min}$ incubation with $\mathrm{ZnS}-\mathrm{PEA}$ nanoconjugates are presented in Figure 8 [TO-PRO-3 emission in red color, first column (a); ZnS-PEA nanoconjugate green emission, second column (b); and third column (c), the overlapping of both biomarkers]. For ZnS-PEA nanoconjugates after $60 \mathrm{~min}$ incubation, the lowest overlapping of green emission (i.e., fluorescence of $\mathrm{ZnS}$ QDs) with the red emission specific for staining nucleus was detected, demonstrating that they were predominantly scattered at the cytosol. 

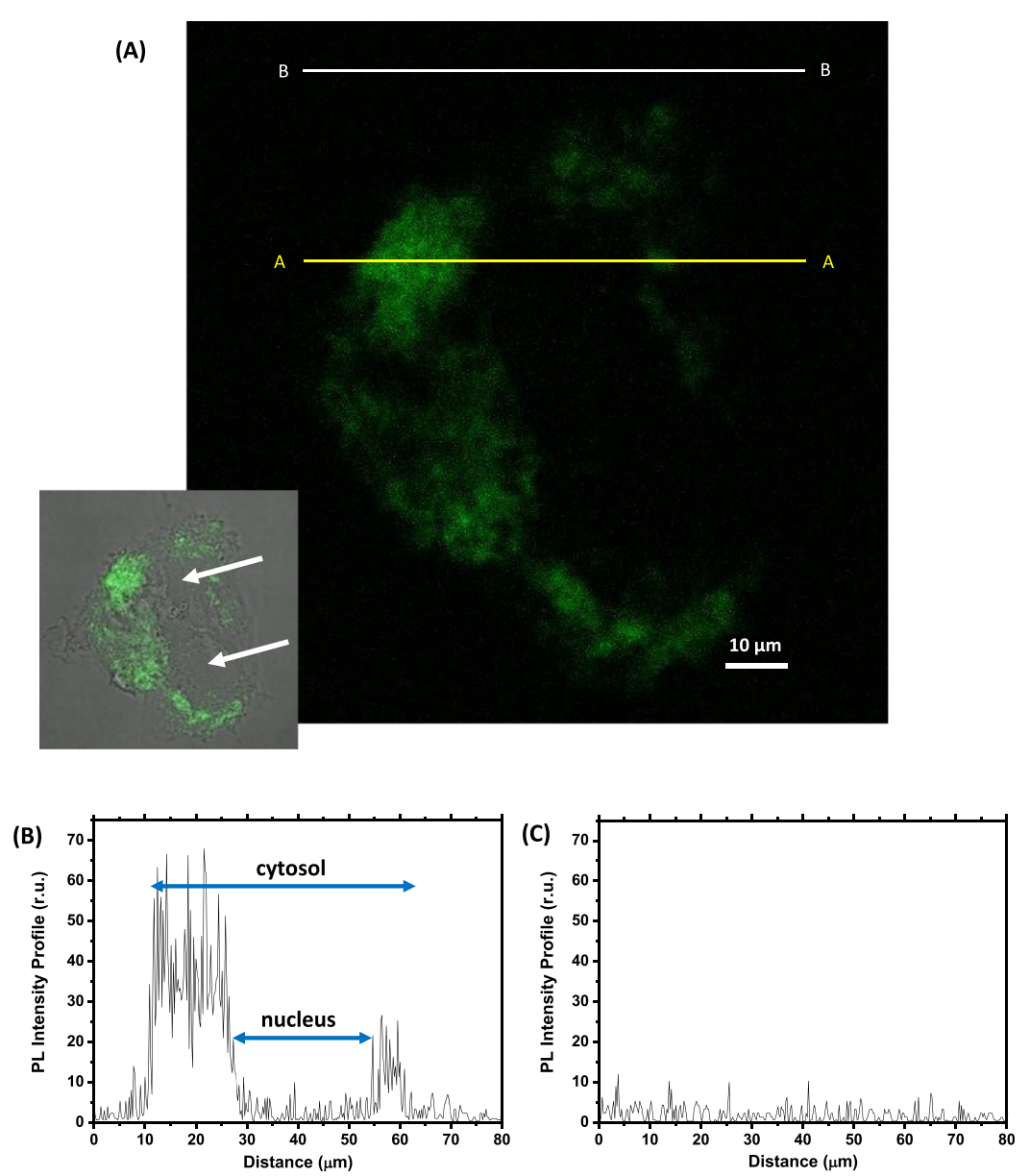

Figure 7. (A) Fluorescence image (inset: bright field and PL images merged; white arrows: nucleus) and intensity fluorescence profiles along (B) $\mathrm{A}-\mathrm{A}$ line and (C) B-B line for MCF7 cell line after $60 \mathrm{~min}$ of incubation with $\mathrm{ZnS}-\mathrm{PEA}$ nanoconjugates.

(a) $\mathrm{TO}^{\mathrm{PRO}}{ }^{\circledR} 3$

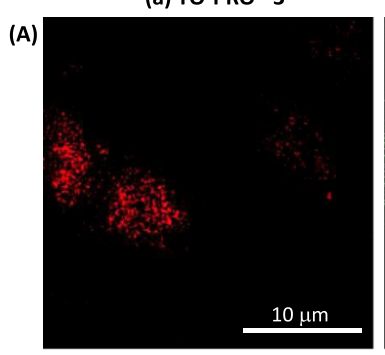

(B)

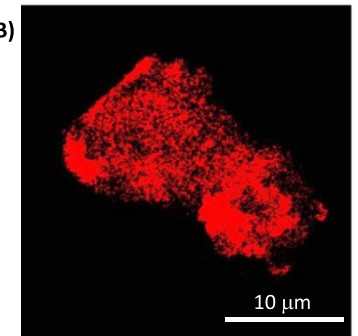

(b) ZnS-PEA
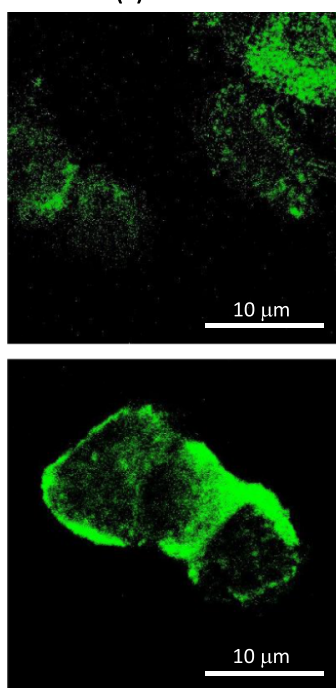

(c) MERGE
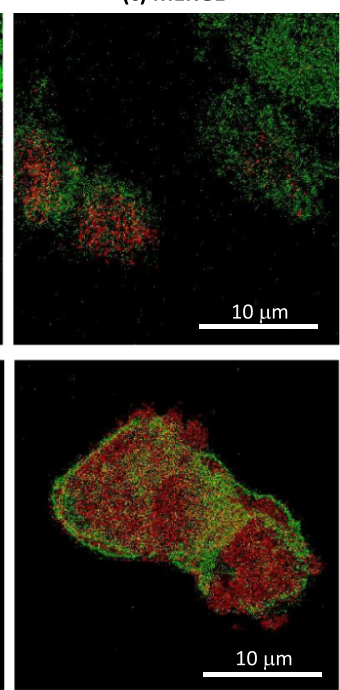

Figure 8. CLSM images showing intracellular uptake and distribution of ZnS-PEA nanoconjugates by (A) SAOS and (B) HEK 293T cells after 60 min of incubation. (a) Images of DNA staining with TO-PRO-3 in red color; (b) images of ZnS-PEA green emission; and (c) merged images of both biomarkers.

For a more comprehensive analysis, a kinetics profile of internalization of $\mathrm{ZnS}-\mathrm{PEA}$ nanoconjugates, the mean fluorescence intensity (MFI) of ZnS-PEA green emission, was estimated using image processing software (ImageJ, v.1.5+, freely available public domain) for osteosarcoma-derived, adenocarcinoma breast, and embryonic kidney cells, and the results are presented in Figure 9. The plot indicated a timedependent enhancement of the relative fluorescent intensity 


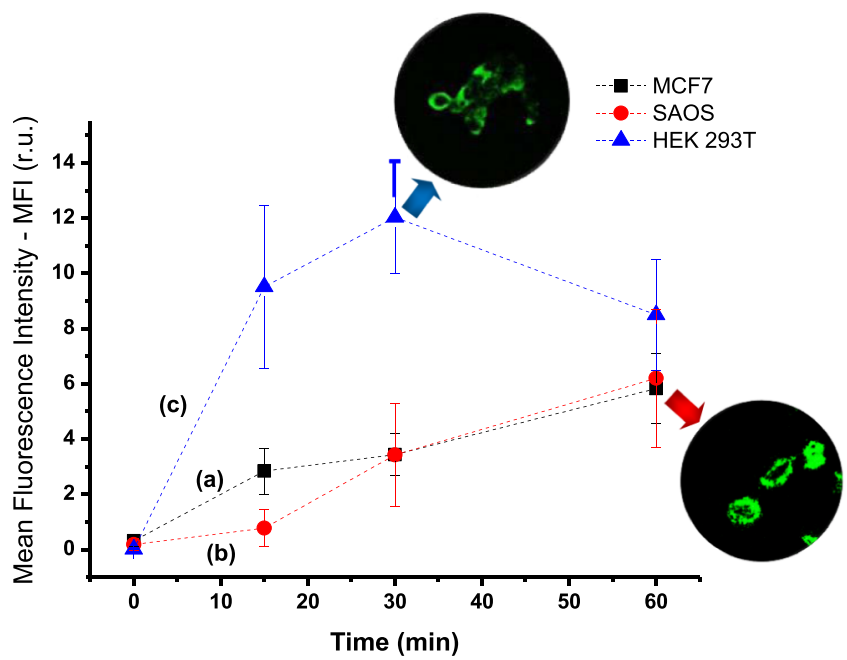

Figure 9. Cell uptake profile based on MFI as function of incubation time for (a) MCF7, (b) SAOS, and (c) HEK 293T cell lines.
(MFI) with the increase of incubation time proving the crescent cell uptake of the $\mathrm{ZnS}$ QD-PEA nanoconjugates, which is assigned to the endocytic pathway. For HEK 293T cell line, the relatively higher values of MFI can be associated with the permeability of this cell line, which has been reported to be model for cell transfection studies. ${ }^{30} \mathrm{~A}$ gradual increase of nanoparticle internalization was also observed as the time evolved until reaching the equilibrium (i.e., depletion of the concentration of nanoparticles at the cell membrane interface and cellular metabolism with exocytosis), suggesting that the saturation stage of intracellular uptake was achieved. ${ }^{42}$ In addition, when considering that the metabolism of cancer cells is accelerated compared to normal cells associated with the lower $\mathrm{pH}$ of extracellular and intracellular microenvironments $(\sim \mathrm{pH} 4.0-5.5)$, the relative lower MFI was attributed to the faster consumption of PEA biomolecule combined with the destruction of $\mathrm{ZnS}-\mathrm{PEA}$ nanoconjugates by cancer cells. This indicated the effects of destruction $\mathrm{ZnS}-\mathrm{PEA}$ conjugates by cancer cells possibly mediated by enzymatic reactions following the phospholipid (i.e., FA) metabolic pathways combined with expected quenching effect of QDs internalized

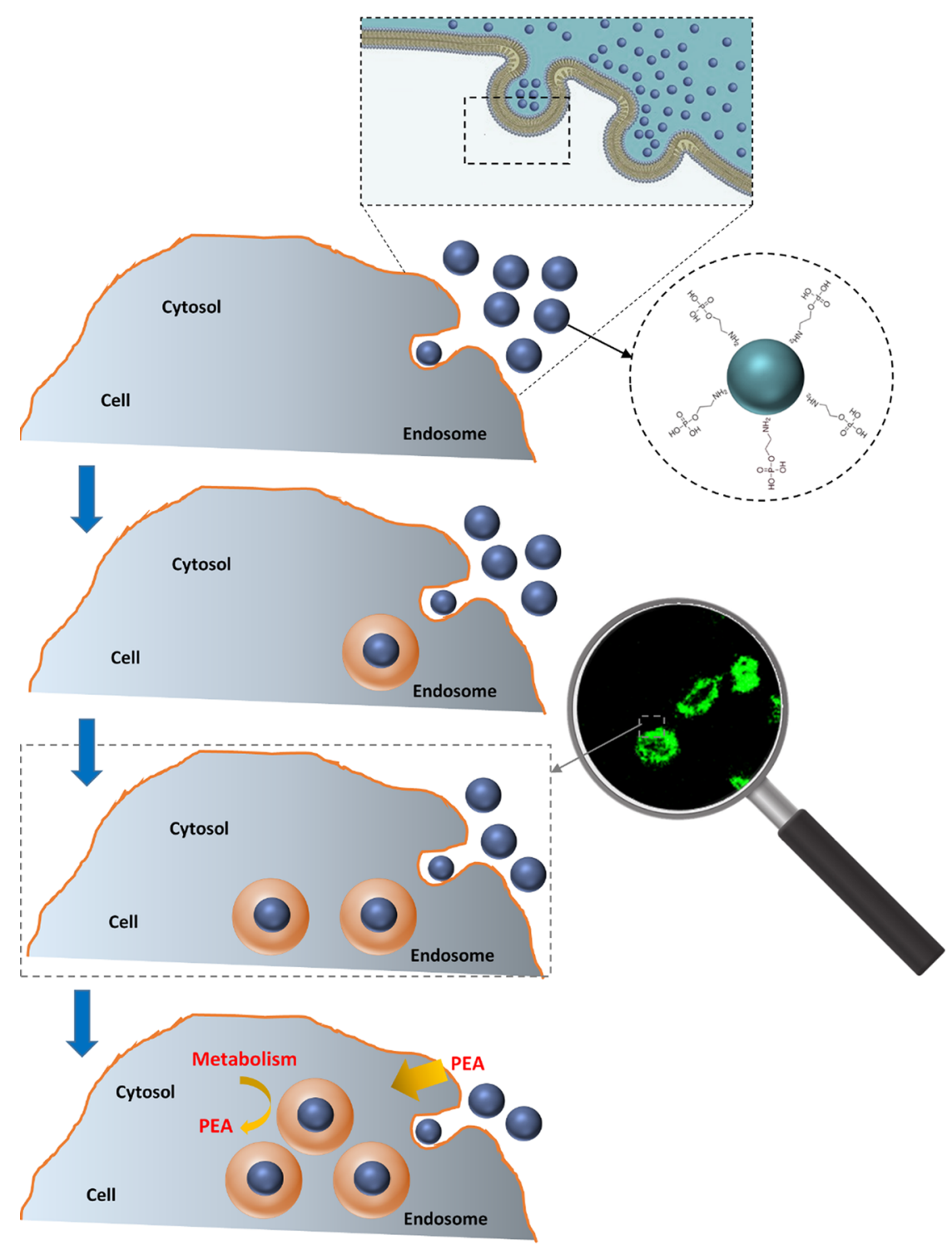

Figure 10. Schematic representation of cellular uptake and endocytosis pathway of $\mathrm{ZnS}-\mathrm{PEA}$ conjugates (not to scale). 
by endolysosomal compartments. These aspects resulted in less accumulation of fluorescent nanoprobes inside malignant cells compared with normal cells.

The increase of PL intensity verified with the incubation time is consistent with one of the primary features for biosensing, demonstrating promising characteristics of these innovative $\mathrm{ZnS}-\mathrm{PEA}$ conjugates to be utilized as fluorescent nanoprobes for cell bioimaging and tracking in cancer research. It is well known that QDs uptake by cells occurs through several pathways, including endocytosis, transfection, and peptide-mediated delivery.

Endocytosis marks the entry of internalized receptors, biomolecules, and conjugates into the complex network of endocytic trafficking pathways. ${ }^{43,44}$ Despite the existence of numerous internalization routes, early endosomes serve as a focal point of the endocytic pathway, which determine the subsequent fate of internalized macromolecules such as proteins and lipids, destining them either for recycling to the plasma membrane, degradation in lysosomes, or delivery to the trans-Golgi network. ${ }^{40,43-45}$ To this end, on the basis of the results of confocal microscopy bioimaging, a schematic representation of the interactions of the novel $\mathrm{ZnS}-\mathrm{PEA}$ nanoconjugates with cancer cells at the biointerfaces is depicted in Figure 10. As an additional tool for evidencing that $\mathrm{ZnS}-\mathrm{PEA}$ conjugates were transported along the endosomal-lysosomal pathways, acidic organelle marker LysoTracker was used for staining late endosomes and lysosome of SAOS cells. The results of $\mathrm{ZnS}-\mathrm{PEA}$ nanoconjugates (Figure 11) showed good co-localization with the lysosomes vesicles of cells, as revealed by the presence of yellow dots in the images caused by overlapping the green fluorescence from $\mathrm{ZnS}-\mathrm{PEA}$ nanoparticles with the red fluorescence from lysosome marker. It should be emphasized that it is a primary assessment with a simplified approach of the
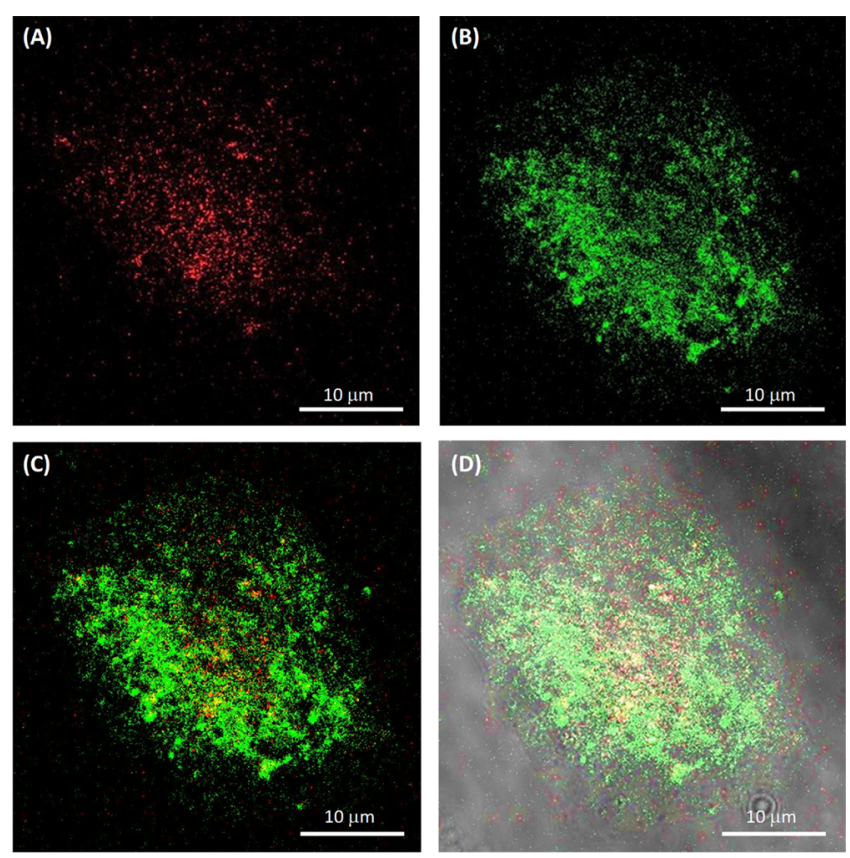

Figure 11. Fluorescence images showing (A) red emission of LysoTracker, (B) green emission of $\mathrm{ZnS}-\mathrm{PEA}$, (C) overlapped CLSM images of red and green emissions, and (D) bright field image + overlapped PL emissions for SAOS cells after 60 min of incubation with $\mathrm{ZnS}-\mathrm{PEA}$ QD. very complex phenomena involving the internalization of biomolecules such as PEA, which participates in several cellular processes, such as in de novo biosynthesis of FAs and phospholipids (via a branch of the Kennedy pathway) by cancer cells. $^{6-10}$ Thus, we attempted to schematically illustrate the conceivable cellular uptake by endocytic pathways of $\mathrm{ZnS}$ QD-PEA nanoconjugates detected by fluorescent bioimaging, as hypothesized, designed and synthesized in this research. Importantly, this study mainly focused on combining the chemical stabilization with the biological function of PEA for building novel fluorescent nanoconjugates for cell bioimaging. Besides the selection of PEA as an innovative biomarker for developing the fluorescent $\mathrm{ZnS}-\mathrm{QD}$ nanoconjugates, it also relied on its water-solubility, distinct from the large majority of FAs and phospholipids, which are predominantly insoluble or poorly soluble in water. In this sense, the results demonstrated that PEA can be potentially used as an active functional biomolecule conjugated to fluorescent nanoparticles (e.g., $\mathrm{ZnS}$ QDs) for prospective bioimaging, biolabeling, and nanosensing applications for investigating lipid-related molecules and other biochemical species involved in cellular metabolism. Though, it must be highlighted that a more in-depth and comprehensive understanding of the intricate cellular process of the internalization, involving energy-dependent routes, expression of cytokines, subcellular localization, and distribution of nanoconjugates (e.g., cytosol compartments and nuclei) are beyond the scope of this study and yet not totally understood in the literature. ${ }^{40,45}$

\section{CONCLUSIONS}

This study proved that $\mathrm{ZnS}-\mathrm{PEA}$ nanoconjugates were designed and synthesized using strictly green colloidal aqueous process. They featured core-shell nanostructures (inorganicorganic) composed by fluorescent $\mathrm{ZnS}$ QDs surrounded by PEA biomolecules forming chemically stable nanocolloids. Additionally, they presented no cytotoxicity after $48 \mathrm{~h}$ of incubation at crescent concentrations using in vitro cell mitochondrial activity with five distinct human cancer cell types (lymphoma, glioma, breast cancer, osteosarcoma, and cervical cancer) and normal cells (HEK $293 \mathrm{~T}$ ) as reference. Importantly, the results of CLSM demonstrated that the $\mathrm{ZnS}-$ PEA nanoconjugates behaved effectively as active fluorescent bioprobes which were internalized by cancer cells with uptake profiles dissimilar from normal cells. Hence, it can be envisioned that these novel $\mathrm{ZnS}-\mathrm{PEA}$ nanoconjugates composed by fluorescent semiconductor core and functional biomolecule shell (i.e., $\mathrm{ZnS}$ QD core, PEA shell) can be potentially used as nanoprobes for bioimaging external and intracellular signaling events related to metabolism of normal and cancer cells. Moreover, they can also be associated with specific biomarkers for tracking endocytic pathways of cancer cells because they proved consistent time-dependent internalization via transport across the cell plasma membrane and intracellular trafficking inside the cytosol.

\section{MATERIALS AND METHODS}

4.1. Materials. PEA ( $\left.>98 \%, \mathrm{NH}_{2} \mathrm{CH}_{2} \mathrm{CH}_{2} \mathrm{OPO}_{3} \mathrm{H}_{2}\right)$, doxorubicin hydrochloride (DOX, $\geq 98.0 \%)$, zinc chloride $\left(\geq 98 \%, \mathrm{ZnCl}_{2}\right)$, MTT (>98\%), Triton X-100, sodium dodecyl sulfate (SDS, $\geq 99.0 \%$ ), paraformaldehyde (95\%), and hydrochloric acid $(\mathrm{HCl}, 37 \%)$ were supplied by Sigma-Aldrich (USA). Sodium sulfide nonahydrate $\left(\mathrm{Na}_{2} \mathrm{~S} \cdot 9 \mathrm{H}_{2} \mathrm{O},>98 \%\right)$ was 
purchased from Synth (Brazil) and sodium hydroxide ( $\geq 99 \%$, $\mathrm{NaOH}$ ) was supplied by Merck (USA). Dulbecco's modified Eagle medium (DMEM), fetal bovine serum (FBS), Roswell Park Memorial Institute Medium for cell culture (RPMI1640), phosphate buffered saline (PBS), penicillin G sodium $\left(\mathrm{C}_{16} \mathrm{H}_{17} \mathrm{~N}_{2} \mathrm{NaO}_{4} \mathrm{~S}, 356.37 \mathrm{~g} \cdot \mathrm{mol}^{-1}\right)$, streptomycin sulfate, and amphotericin-b were supplied by Gibco BRL (USA). Hydromount was purchased from Fisher Scientific Ltd. (UK). TOPRO-3 and LysoTracker Red DND-99 were purchased from Invitrogen (USA).

The immortalized human carcinoma-derived (HeLa, ATCC CCL-2) cells, human embryonic kidney cell (HEK 293T, ATCC CRL-1573) cells, and immortalized human osteosarcoma-derived (SAOS, ATCC HTB-85) cells were gently provided by Federal University of Minas Gerais (UFMG). Human brain likely glioblastoma (U-87 MG, ATCC HTB-14), human breast adenocarcinoma (MCF7, ATCC HTB-22), and human non-Hodgkin's B cell lymphoma (NHL, Toledo, ATCC CRL-2631) cell lines were procured from Brazilian Cell Repository (Banco de Células do Rio de Janeiro: BCRJ, Brazil; cell line authentication molecular technique, short tandem repeat DNA; quality assurance according to the international standard NBR ISO/IEC 17 025:2005). All abovementioned chemicals were used "as supplied" without additional purification protocols. Deionized water (DI water, Millipore Simplicity, resistivity $18.0 \mathrm{M} \Omega \cdot \mathrm{cm}$ ) was used to prepare all the solutions, and the syntheses were performed at room temperature $\left(23 \pm 2{ }^{\circ} \mathrm{C}\right)$, unless specified otherwise.

4.2. Synthesis and Characterization of ZnS Quantum Dots with PEA Functional Ligand (ZnS-PEA). The synthesis and characterization of ZnS QDs in aqueous medium were performed using the adapted colloidal process developed by our group, ${ }^{46}$ where the functional molecule (e.g., PEA) acted as capping ligand for the stabilization of the nanoparticles. Essentially, PEA solution $(2.5 \% \mathrm{w} / \mathrm{v})$ was prepared by adding O-PEA powder $(0.25 \mathrm{~g})$ to $10 \mathrm{~mL}$ of DI water with moderate stirring at room temperature for $10 \mathrm{~min}$. $\mathrm{ZnS}$ QDs were synthesized via a facile one-pot aqueous process as follows: $10 \mathrm{~mL}$ PEA solution was added to the reaction flask. In the sequence, under moderate magnetic stirring, the $\mathrm{pH}$ was adjusted to $8.0 \pm 0.5\left(\mathrm{NaOH}, 0.1 \mathrm{~mol} \cdot \mathrm{L}^{-1}\right)$ and the total volume was completed to $45.5 \mathrm{~mL}$ with $\mathrm{DI}$ water. Then, 2.0 $\mathrm{mL}$ of $\mathrm{Zn}^{2+}$ salt solution $\left(\mathrm{ZnCl}_{2}, 1.0 \times 10^{-2} \mathrm{~mol} \cdot \mathrm{L}^{-1}\right)$ and 2.5 $\mathrm{mL}$ of $\mathrm{S}^{2-}$ salt solution $\left(\mathrm{Na}_{2} \mathrm{~S} \cdot 9 \mathrm{H}_{2} \mathrm{O}, 8 \times 10^{-3} \mathrm{~mol} \cdot \mathrm{L}^{-1}\right)$ were added to the flask ( $\mathrm{S} / \mathrm{Zn}$ molar ratio was kept at 1:1) and kept under moderate magnetic stirring for $10 \mathrm{~min}$. The $\mathrm{ZnS}-\mathrm{PEA}$ QD colloidal dispersions $(1.0 \mu \mathrm{M}$ and equivalent PEA concentration $=40 \mathrm{mM}$ ) produced were chemically stable, homogeneous, clear, and colorless. This concentration of PEA was required for chemical stabilization of the $\mathrm{ZnS}$ QDs in aqueous medium. These ZnS QD nanocolloids were dialyzed for $24 \mathrm{~h}$ against $3 \mathrm{~L}$ of DI water (with water replacements after 2 and $4 \mathrm{~h}$ ) using a Pur-A-Lyzer Mega Dialysis Kit (Sigma, cellulose membrane with molecular weight cut-off filter, MWCO of $12000 \mathrm{Da}$ ) under moderate magnetic stirring at room temperature. After the purification process, the $\mathrm{ZnS}$ QD dispersions were stored at $6 \pm 2{ }^{\circ} \mathrm{C}$ until further use.

UV-vis spectroscopy measurements were executed in transmission mode (PerkinElmer, Inc., USA, equipment Lambda EZ-210) with samples placed in quartz cuvettes scanning from visible to ultraviolet region (i.e., $\lambda=600-190$ $\mathrm{nm})$. All of the experiments were performed in triplicate $(n=$
3) unless specified otherwise, and the data measurements were presented as the average \pm standard deviation.

$\mathrm{PL}$ analysis of $\mathrm{ZnS}$ bioconjugates was performed at room temperature using a high-power xenon light source (HPX2000, 35 W xenon source, Mikropack, Germany) combined with an Ocean Optics USB2000 UV-vis spectrophotometer (Ocean Optics, Inc., USA). All of the experiments were performed using at least four repetitions $(n \geq 4)$. Photoluminescence $\mathrm{QY}$ of $\mathrm{ZnS}-\mathrm{PEA}$ nanoconjugates was acquired according to the conventional comparative procedure using quinine sulfate in $\mathrm{H}_{2} \mathrm{SO}_{4}(0.5 \mathrm{M}, \mathrm{QY}=0.55$, Sigma-Aldrich Co., St Louis, MO, USA) as the standard at $\lambda_{\text {excitation }}=350$ $\mathrm{nm}^{23,47}$

The morphological characterization of $\mathrm{ZnS}-\mathrm{PEA}$ nanostructures was performed using a transmission electron microscope (Tecnai G2-20-FEI, FEI Company, USA) at an accelerating voltage of $200 \mathrm{kV}$, where images and SAED patterns were acquired. Prior to TEM analyses, the samples were prepared by placing droplets of dilute $\mathrm{ZnS}-\mathrm{PEA}$ suspension onto carbon-coated copper grids (Electron Microscopy Sciences, USA) and drying at room temperature overnight. The average size and size-distribution data were obtained using the TEM images by measuring at least 150 randomly selected $\mathrm{ZnS}$ nanoparticles calculated with image processing program (ImageJ, v.1.50+, public domain, National Institutes of Health).

DLS (also referred to as photon correlation spectroscopy) and zeta potential (ZP or $\zeta$-potential) characterizations were performed using ZetaPlus instrument (Brookhaven Instruments Corporation, $35 \mathrm{~mW}$ red diode laser light, wavelength $\lambda$ $=660 \mathrm{~nm})$ with at least 10 repetitions $(n \geq 10)$. The ZP measurements were executed at temperature of $25.0 \pm 2{ }^{\circ} \mathrm{C}$ using the Smoluchowski equation method with minimum 10 replicates.

4.3. Nanoconjugates for Cell Bioimaging and Tracking. The ISO 10993-5:2009/(R)2014 standard (Biological evaluation of medical devices: tests for in vitro cytotoxicity) was used for all of the biological tests performed in this study because it is widely accepted as a reliable methodology for accessing the biological responses toward new materials and devices. $^{4}$ The cells (HEK 293T, passages 18 and 41; U-87 MG, passage 8 ; HeLa, passage 89; SAOS, passages 15 and 52) were cultivated in DMEM with $10 \%$ FBS, amphotericin-b (0.025 $\left.\mathrm{mg} \cdot \mathrm{mL}^{-1}\right)$, streptomycin sulfate $\left(10 \mathrm{mg} \cdot \mathrm{mL}^{-1}\right)$, and penicillin $\mathrm{G}$ sodium ( 10 units $\mathrm{mL}^{-1}$ ) in a humidified atmosphere of $5 \%$ $\mathrm{CO}_{2}$ at $37{ }^{\circ} \mathrm{C}$. In addition, MCF7 (passage 29) and Toledo (passage 16) cancer cells were cultured in RPMI-1640 medium with the same abovementioned supplements and conditions.

4.3.1. In Vitro Cell Viability Assays Using Cancer Cell Lines. As one of the most widely used cell viability bioassays, ${ }^{4,20,40}$ MTT experiments were performed accordingly to previous reports of our group ${ }^{4,40,48}$ to assess the in vitro cytotoxicity of PEA and ZnS-PEA QDs. All of the cells were plated $\left(1 \times 10^{4}\right.$ cells/well $)$ in 96-well plates and the cell populations were synchronized in serum-free media for $24 \mathrm{~h}$. Then, the media volume was suctioned and replaced with DMEM or RPMI-1640 media containing 10\% FBS for $24 \mathrm{~h}$. In the sequence, PEA solutions (blank reference molecule) were added to individual wells at crescent final concentrations of 0.1 , $1.0,10$, or $100 \mu \mathrm{M}$ for $48 \mathrm{~h}$, and $\mathrm{ZnS}-\mathrm{PEA}$ solution was added at $1 \%(\mathrm{v} / \mathrm{v}$, i.e., $350 \mu \mathrm{M}$ of PEA biomolecule; $10 \mathrm{nM}$ of colloidal nanoconjugates) of concentration for 48 h, 5 days, and 7 days. Control samples were prepared as follows: control 
group (cell culture with DMEM or RPMI-1640 media); positive control (1.0\% v/v Triton X-100 in PBS); and negative control (chips of sterile polypropylene Eppendorf, $1 \mathrm{mg} \cdot \mathrm{mL}^{-1}$, Eppendorf, Germany). After the specified time of incubation, all media were aspirated and replaced with $60 \mu \mathrm{L}$ of culture media containing serum to each well and images of cells were acquired by using an inverted microscope (Leica DMIL LED, Germany). Then, $50 \mu \mathrm{L}$ of MTT $\left(5 \mathrm{mg} \cdot \mathrm{mL}^{-1}\right)$ was added to each well and incubated for $4 \mathrm{~h}$ in an oven at a temperature of $37{ }^{\circ} \mathrm{C}$ and an atmosphere of $5 \% \mathrm{CO}_{2}$. Next, $40 \mu \mathrm{L}$ of SDS solution/4\% $\mathrm{HCl}$ was placed in each well and incubated for 16 $\mathrm{h}$ in an oven at $37{ }^{\circ} \mathrm{C}$ and $5 \% \mathrm{CO}_{2}$. Lastly, $100 \mu \mathrm{L}$ were removed from each well and transferred to a 96-well plate and spectroscopy absorbance measurements were performed at $\lambda=$ 595 nm (iMark Microplate Absorbance Reader, Bio-Rad). The percentage of cell viability was calculated according to eq $2,4,40,48$ where the values of the controls (i.e., wells with cells but without nanoconjugate samples) were fixed to $100 \%$ cell viability.

$$
\text { Cell viability }=(\text { absorbance of sample and cells })
$$

$$
/(\text { absorbance of control) } \times 100 \%
$$

4.3.2. Fluorescent ZnS-PEA Nanomarkers for Bioimaging and Detection of Cancer Cells. The evaluation of the $\mathrm{ZnS}-$ PEA nanoconjugates as fluorescent biological probes for in vitro bioimaging was performed using CLSM after exposing SAOS, MCF7, and HEK 293T cell lines to ZnS-PEA QDs, following similar procedures reported by our group. ${ }^{4,46}$ Cells were plated $\left(5 \times 10^{5}\right.$ cells per well $)$ in 6-well plate, incubated for 4 days in $5 \% \mathrm{CO}_{2}$ at $37{ }^{\circ} \mathrm{C}$, and synchronized for $24 \mathrm{~h}$. Then, ZnS-PEA colloidal suspensions (1:1) with the medium solution (DMEM or RPMI-1640 with $10 \%$ FBS) were added to the cells and incubated in $5 \% \mathrm{CO}_{2}$ at $37{ }^{\circ} \mathrm{C}$ for 15,30 , and $60 \mathrm{~min}$ (for cellular uptake kinetics study), followed by washing with PBS solution. In the sequence, the cells were fixed with paraformaldehyde (4.0\% in PBS) for $30 \mathrm{~min}$ and washed three times with PBS, and cover slips were mounted with hydromount. Then, the images were captured using a confocal microscope (Zeiss LSM Meta 510, Carl Zeiss, Germany) by water immersion objectives (objective $63 \times$ Plan-Apo/1.4 NA). Excitation was performed by argon laser at $\lambda_{\text {exc }}=488 \mathrm{~nm}$ and emission was collected at $\lambda=505-550 \mathrm{~nm}$. For the reference control (i.e., autofluorescence), cells were incubated using only the original medium with $10 \%$ FBS (i.e., without nanoconjugates). Plot of intensity profiles and MFI measurements were executed using image processing software (ImageJ software, version 1.50, public domain, $\mathrm{NIH}$ ).

In order to perform selective staining of the nuclei of the HEK $293 \mathrm{~T}$ and SAOS cells, after the incubation procedure with $\mathrm{ZnS}-\mathrm{PEA}$ conjugates for $60 \mathrm{~min}$, the samples were washed with PBS and treated with TO-PRO-3 (i.e., following the manufacturer's protocol). Moreover, for tracking the cellular endosomal-lysosomal pathways, SAOS cells were incubated with $\mathrm{ZnS}-\mathrm{PEA}$ nanoconjugates for $60 \mathrm{~min}$, washed with PBS, and then stained with specific dye for lysosome vesicles (LysoTracker Red DND-99) based on the manufacturer's protocol. In the sequence, digital images were captured with an Eclipse $\mathrm{Ti}$ confocal microscope (Nikon Instruments, USA) using the oil immersion objective (63× Plan-Apo/1.4 NA). Excitation was performed by argon laser at $\lambda_{\text {exc }}=488 \mathrm{~nm}$ (fluorescein isothiocyanate) and emission was collected at $\lambda=$ 506-550 nm. In addition, excitation at $\lambda=543 \mathrm{~nm}$ (tetramethylrhodamine) and observation at $\lambda=545-645 \mathrm{~nm}$ were chosen for detecting red fluorescence of TO-PRO-3 and LysoTracker. Dual-color confocal fluorescence images were recorded separately in the correspondent channel and merged afterward for proceeding with bioimaging analysis and characterization.

\section{ASSOCIATED CONTENT}

\section{S Supporting Information}

The Supporting Information is available free of charge on the ACS Publications website at DOI: 10.1021/acsomega.8b02098.

Cell viability responses by MTT assay after $48 \mathrm{~h}$ of incubation with PEA and DOX at different concentrations (PDF)

\section{AUTHOR INFORMATION}

\section{Corresponding Author}

*E-mail: hmansur@demet.ufmg.br. Phone/Fax: +55-3134091843 (H.S.M.).

ORCID ${ }^{\circ}$

Alexandra A. P. Mansur: 0000-0003-1526-2508

Herman S. Mansur: 0000-0002-3032-495X

\section{Author Contributions}

The manuscript was written through equally contributions of all authors. All authors have given approval to the final version of the manuscript.

\section{Funding}

This study was funded by Brazilian agencies: CAPES (PROEX433/2010; PNPD; PROINFRA2010-2014), FAPEMIG (PPM00760-16; BCN-TEC 30030/12), CNPq (PQ1B-306306/ 2014-0; UNIVERSAL-457537/2014-0; PIBIC-2014/2015), and FINEP (CTINFRA-PROINFRA 2008/2010/2011).

\section{Notes}

The authors declare no competing financial interest. This article does not contain any studies with human participants or animals performed by any of the authors.

\section{ACKNOWLEDGMENTS}

The authors acknowledge the financial support from the Brazilian research agencies. The authors express their gratitude to the staff of Microscopy Center for their assistance with HRTEM/SAED analysis and the staff at the Center of Nanoscience, Nanotechnology and Innovation-CeNano ${ }^{2} \mathrm{I} /$ CEMUCASI/UFMG for the spectroscopy analyses.

\section{REFERENCES}

(1) Strebhardt, K.; Ullrich, A. Paul Ehrlich's magic bullet concept: 100 years of progress. Nat. Rev. Cancer 2008, 8, 473-480.

(2) Scott, A. M.; Wolchok, J. D.; Old, L. J. Antibody therapy of cancer. Nat. Rev. Cancer 2012, 12, 278-287.

(3) Chen, H.; Zhang, W.; Zhu, G.; Xie, J.; Chen, X. Rethinking cancer nanotheranostics. Nat. Rev. Mater. 2017, 2, 17024.

(4) Mansur, A. A. P.; Carvalho, S. M.; Lobato, Z. I. P.; Leite, M. F.; Cunha, A. S., Jr.; Mansur, H. S. Design and Development of Polysaccharide-Doxorubicin-Peptide Bioconjugates for Dual Synergistic Effects of Integrin-Targeted and Cell-Penetrating Peptides for Cancer Chemotherapy. Bioconjugate Chem. 2018, 29, 1973-2000.

(5) Santos, C. R.; Schulze, A. Lipid metabolism in cancer. FEBS J. 2012, 279, 2610-2623. 
(6) Carracedo, A.; Cantley, L. C.; Pandolfi, P. P. Cancer metabolism: fatty acid oxidation in the limelight. Nat. Rev. Cancer 2013, 13, 227232.

(7) Weinberg, S. E.; Chandel, N. S. Targeting mitochondria metabolism for cancer therapy. Nat. Chem. Biol. 2015, 11, 9-15.

(8) Kuznetsova, L.; Chen, J.; Sun, L.; Wu, X.; Pepe, A.; Veith, J. M.; et al. Syntheses and evaluation of novel fatty acid-second-generation taxoid conjugates as promising anticancer agents. Bioorg. Med. Chem. Lett. 2006, 16, 974-977.

(9) Fullerton, M. D.; Hakimuddin, F.; Bonen, A.; Bakovic, M. The Development of a Metabolic Disease Phenotype in CTP:Phosphoethanolamine Cytidylyltransferase-deficient Mice. J. Biol. Chem. 2009, 284, 25704-25713.

(10) Liu, Q.; Luo, Q.; Halim, A.; Song, G. Targeting lipid metabolism of cancer cells: a promising therapeutic strategy for cancer. Cancer Lett. 2017, 401, 39-45.

(11) Peck, B.; Schulze, A. Lipid desaturation-the next step in targeting lipogenesis in cancer? FEBS J. 2016, 283, 2767-2778.

(12) Dhakshinamoorthy, S.; Dinh, N.-T.; Skolnick, J.; Styczynski, M. P. Metabolomics identifies the intersection of phosphoethanolamine with menaquinone-triggered apoptosis in an in vitro model of leukemia. Mol. BioSyst. 2015, 11, 2406-2416.

(13) Aroui, S.; Brahim, S.; Waard, M. D.; Kenani, A. Cytotoxicity, intracellular distribution and uptake of doxorubicin and doxorubicin coupled to cell-penetrating peptides in different cell lines: A comparative study. Biochem. Biophys. Res. Commun. 2010, 391, 419-425.

(14) Gohil, V. M.; Zhu, L.; Baker, C. D.; Cracan, V.; Yaseen, A.; Jain, M.; et al. Meclizine inhibits mitochondrial respiration through direct targeting of cytosolic phosphoethanolamine metabolism. J. Biol. Chem. 2013, 288, 35387-35395.

(15) Wu, L.; Qu, X. Cancer biomarker detection: recent achievements and challenges. Chem. Soc. Rev. 2015, 44, 2963-2997.

(16) Menendez, J. A.; Lupu, R. Fatty acid synthase and the lipogenic phenotype in cancer pathogenesis. Nat. Rev. Cancer 2007, 7, 763777.

(17) Kievit, F. M.; Zhang, M. Cancer nanotheranostics: improving imaging and therapy by targeted delivery across biological barriers. Adv. Mater. 2011, 23, $\mathrm{H} 217-\mathrm{H} 247$.

(18) Xu, G.; Zeng, S.; Zhang, B.; Swihart, M. T.; Yong, K.-T.; Prasad, P. N. New generation cadmium-free quantum dots for biophotonics and nanomedicine. Chem. Rev. 2016, 116, 1223412327.

(19) Hildebrandt, N. Biofunctional quantum dots: Controlled conjugation for multiplexed biosensors. ACS Nano 2011, 5, 52865290.

(20) Oh, E.; Liu, R.; Nel, A.; Gemill, K. B.; Bilal, M.; Cohen, Y.; et al. Meta-analysis of cellular toxicity for cadmium-containing quantum dots. Nat. Nanotechnol. 2015, 11, 479-486.

(21) Ramanery, F. P.; Mansur, A. A. P.; Mansur, H. S. One-step colloidal synthesis of biocompatible water-soluble $\mathrm{ZnS}$ quantum dot/ chitosan nanoconjugates. Nanoscale Res. Lett. 2013, 8, 512.

(22) Mansur, H. S.; Mansur, A. A. P.; Soriano-Araújo, A.; Lobato, Z. I. P.; de Carvalho, S. M.; Leite, M. F. Water-soluble nanoconjugates of quantum dot-chitosan-antibody for in vitro detection of cancer cells based on "enzyme-free" fluoroimmunoassay. Mater. Sci. Eng., C 2015, $52,61-71$.

(23) Mansur, H. S.; Mansur, A. A. P.; Soriano-Araújo, A.; Lobato, Z. I. P. Beyond biocompatibility: an approach for the synthesis of $\mathrm{ZnS}$ quantum dot-chitosan nano-immunoconjugates for cancer diagnosis. Green Chem. 2015, 17, 1820-1830.

(24) Gruhl, F. J.; Rapp, B. E.; Länge, K. Biosensors for Diagnostic Applications. Adv. Biochem. Eng./Biotechnol. 2013, 133, 115-148.

(25) Freitas, D. V.; Passos, S. G. B.; Dias, J. M. M.; Mansur, A.; Carvalho, S. M.; Mansur, H.; Navarro, M. Toward greener electrochemical synthesis of composition-tunable luminescent CdXbased $(\mathrm{X}=\mathrm{Te}$, Se, $\mathrm{S})$ quantum dots for bioimaging cancer cells. Sens. Actuators, B 2017, 250, 233-243.
(26) Mansur, H. S. Quantum dots and nanocomposites. Wiley Interdiscip. Rev.: Nanomed. Nanobiotechnol. 2010, 2, 113-129.

(27) Mansur, A. A. P.; Mansur, H. S.; Soriano-Araújo, A.; Lobato, Z. I. P. Fluorescent nanohybrids based on quantum dot-chitosanantibody as potential cancer biomarkers. ACS Appl. Mater. Interfaces 2014, 6, 11403-11412.

(28) Murcia, M. J.; Minner, D. E.; Mustata, G.-M.; Ritchie, K.; Naumann, C. A. Design of quantum dot-conjugated lipids for longterm, high-speed tracking experiments on cell surfaces. J. Am. Chem. Soc. 2008, 130, 15054-15062.

(29) Papagiannaros, A.; Levchenko, T.; Hartner, W.; Mongayt, D.; Torchilin, V. Quantum dots encapsulated in phospholipid micelles for imaging and quantification of tumors in the near-infrared region. Nanomedicine 2009, 5, 216-224.

(30) Carvalho, S. M.; Mansur, H. S.; Ramanery, F. P.; Mansur, A. A. P.; Lobato, Z. I. P.; Leite, M. F. Cytotoxicity investigation of luminescent nanohybrids based on chitosan and carboxymethyl chitosan conjugated with $\mathrm{Bi}_{2} \mathrm{~S}_{3}$ quantum dots for biomedical applications. Toxicol. Res. 2016, 5, 1017-1028.

(31) Sohaebuddin, S. K.; Thevenot, P. T.; Baker, D.; Eaton, J. W.; Tang, L. Nanomaterial cytotoxicity is composition, size, and cell type dependent, Part. Part. Fibre Toxicol. 2010, 7, 22.

(32) Jaiswal, A.; Sanpui, P.; Chattopadhyay, A.; Ghosh, S. S. Investigating fluorescence quenching of $\mathrm{ZnS}$ quantum dots by silver nanoparticles. Plasmonics 2011, 6, 125-132.

(33) Mall, M.; Kumar, L. Optical studies of $\mathrm{Cd}^{2+}$ and $\mathrm{Mn}^{2+} \mathrm{Co}-$ doped ZnS nanocrystals. J. Lumin. 2010, 130, 660-665.

(34) Mansur, A. A. P.; Mansur, H. S.; Carvalho, S. M.; Caires, A. J. One-Pot Aqueous Synthesis of Fluorescent Ag-In-Zn-S Quantum Dot/Polymer Bioconjugates for Multiplex Optical Bioimaging of Glioblastoma Cells. Contrast Media Mol. Imaging 2017, 2017, 3896107.

(35) Tsui, F. C.; Ojcius, D. M.; Hubbell, W. L. The intrinsic pKa values for phosphatidylserine and phosphatidylethanolamine in phosphatidylcholine host bilayers. Biophys. J. 1986, 49, 459-468.

(36) Fröhlich, E. The role of surface charge in cellular uptake and cytotoxicity of medical nanoparticles. Int. J. Nanomed. 2012, 7, 55775591.

(37) Arvizo, R. R.; Miranda, O. R.; Thompson, M. A.; Pabelick, C. M.; Bhattacharya, R.; Robertson, J. D.; et al. Effect of nanoparticle surface charge at the plasma membrane and beyond. Nano Lett. 2010, $10,2543-2548$.

(38) Forest, V.; Cottier, M.; Pourchez, J. Electrostatic interactions favor the binding of positive nanoparticles on cells: A reductive theory. Nano Today 2015, 10, 677-680.

(39) Nafee, N.; Schneider, M.; Schaefer, U. F.; Lehr, C.-M. Relevance of the colloidal stability of chitosan/PLGA nanoparticles on their cytotoxicity profile. Int. J. Pharm. 2009, 381, 130-139.

(40) Mansur, A. A.; Mansur, H. S.; de Carvalho, S. M.; Lobato, Z. I.; Guedes, M. I.; Leite, M. F. Surface biofunctionalized CdS and ZnS quantum dot nanoconjugates for nanomedicine and oncology: to be or not to be nanotoxic? Int. J. Nanomed. 2016, 11, 4669-4690.

(41) Juzena, P.; Chen, W.; Sun, Y.-P.; Coelho, M. A. N.; Generalov, R.; Generalova, N.; Christensen, I. L. Quantum dots and nanoparticles for photodynamic and radiation therapies of cancer. $A d v$. Drug Delivery Rev. 2008, 60, 1600-1614.

(42) Damalakiene, L.; Karabanovas, V.; Valius, S.; Rotomskis, R.; Bagdonas, R. Intracellular distribution of nontargeted quantum dots after natural uptake and microinjection. Int. J. Nanomed. 2013, 8, $555-568$.

(43) Wang, T.; Bai, J.; Jiang, X.; Nienhaus, G. U. Cellular uptake of nanoparticles by membrane penetration: a study combining confocal microscopy with FTIR spectroelectrochemistry. ACS Nano 2012, 6, 1251-1259.

(44) Yameen, B.; Choi, W. I.; Vilos, C.; Swami, A.; Shi, J.; Farokhzad, O. C. Insight into nanoparticle cellular uptake and intracellular targeting. J. Controlled Release 2014, 190, 485-499.

(45) Marsh, M.; McMahon, H. T. The structural era of endocytosis. Science 1999, 285, 215-220. 
(46) Mansur, A. A. P.; de Carvalho, F. G.; Mansur, R. L.; Carvalho, S. M.; de Oliveira, L. C.; Mansur, H. S. Carboxymethylcellulose/ $\mathrm{ZnCdS}$ fluorescent quantum dot nanoconjugates for cancer cell bioimaging. Int. J. Biol. Macromol. 2017, 96, 675-686.

(47) Brouwer, A. M. Standards for photoluminescence quantum yield measurements in solution (IUPAC Technical Report). Pure Appl. Chem. 2011, 83, 2213-2228.

(48) de Carvalho, S. M.; Mansur, A. A. P.; Mansur, H. S.; Guedes, M. I. M. C.; Lobato, Z. I. P.; Leite, M. F. In vitro and in vivo assessment of nanotoxicity of CdS quantum dot/aminopolysaccharide bionanoconjugates. Mater. Sci. Eng., C 2017, 71, 412-424. 